\title{
Promover e recuperar saúde: sentidos produzidos em grupos comunitários no contexto do Programa de Saúde da Família*
}

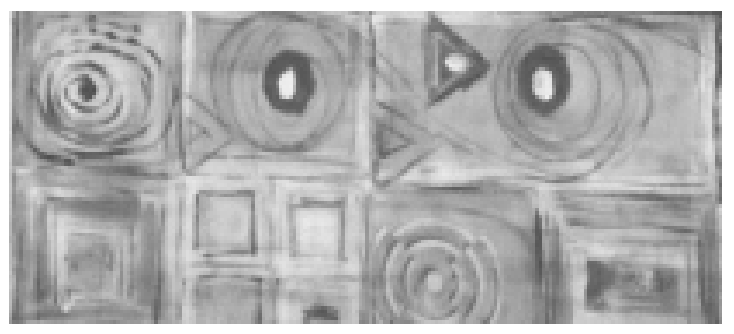

Celiane Camargo Borges ${ }^{1}$

Marisa Japur ${ }^{2}$

CAMARGO-BORGES, C.; JAPUR, M. Promoting and recovering health: meanings produced in community groups within the Family Healthcare Program context. Interface - Comunic., Saúde, Educ., v.9, n.18, p.507-19, set/ dez 2005.

Public Healthcare in Brazil has tended to reflect major changes in the healthcare model. New tendencies point to the importance of actions being built up from their context and focused on specific communities. The objective of this study is to describe the meanings of health / illness as produced by community groups within the context of a Family Healthcare Program. Five groups had their single-session discussions taped and recorded, under the coordination of the first author. This material was transcribed and, coupled with field notes, formed the database for this study. The analysis described the meanings of the ideas on which new healthcare proposals are being based, providing visibility for the multiplicity of meanings and denaturalizing fixed lines of discourse on healthcare / illness. The final thoughts, developed from the point of view of social constructionism, indicate that healthcare practices based on the process of constant conversation and negotiation between all the social actors involved is a fertile ground.

KEY WORDS: family health. community health services. social construcionism.

A Saúde Pública no Brasil tem acompanhado grandes movimentos de mudança do modelo assistencial em saúde. Novas tendências apontam para a importância de ações construídas a partir de seu contexto, voltadas a comunidades específicas. O presente estudo teve por objetivo descrever os sentidos de saúde/doença produzidos em grupos comunitários no contexto de um PSF. Foram audiogravados cinco grupos de sessão única, coordenados pela primeira autora. Os grupos foram transcritos e junto às notas de campo, constituíram a base de dados. A análise descreveu sentidos acerca das noções que vêm embasando as novas propostas em saúde, dando visibilidade à multiplicidade de sentidos, desnaturalizando discursos fixos sobre saúde/doença. As considerações finais, baseadas na perspectiva do construcionismo social, apontam para a fertilidade de uma prática em saúde baseada nos processos de conversação e negociação constantes, entre todos os atores sociais envolvidos.

PALAVRAS-CHAVE: saúde da família. serviços de saúde comunitária. construcionismo social.

"Elaborado a partir de Camargo-Borges (2002), pesquisa com apoio do CNPq.

1 Psicóloga, Departamento de Enfermagem Materno-Infantil e Saúde Pública, Escola de Enfermagem de Ribeirão Preto, Universidade de São Paulo.<celianeborges@gmail.com>

${ }^{2}$ Psicóloga, Departamento de Psicologia e Educação, Faculdade de Filosofia, Ciências e Letras de Ribeirão Preto, Universidade de São Paulo $<$ mjapur@ffclrp.usp.br>

${ }^{1} 14$ McDaniel Drive, box 2081, room 310

Durham, $\mathrm{NH} 03824$

USA

Interface - Comunic, Saúde, Educ, v.9, n.18, p.507-19, set/dez 2005 


\section{Introdução}

Desde o início do século $\mathrm{XX}$, quando a Saúde Pública no Brasil se configurou como política nacional de saúde, vêm-se sistematizando práticas sanitárias na tentativa de estabelecer uma assistência eficaz voltada para a coletividade (Nunes, 2000), tendo sido a criação e regulamentação do SUS os marcos mais importantes desse processo. Após sucessivos movimentos e tentativas, esta foi a primeira ferramenta legitimada e garantida em lei para a construção de um sistema de saúde digno, humano e universal. Desde sua conquista legal, em 1990 (Brasil, 1990), uma profunda reorganização vem ocorrendo e visa operacionalizar as diretrizes e princípios estabelecidos para seu pleno funcionamento.

O Programa de Saúde da Família (PSF), implementado em 1994 (Brasil, 1994), faz parte desta reorganização do sistema, caracterizando-se como estratégia para a conformação de uma rede de cuidados progressivos em saúde no SUS, sendo responsável pela atenção primária e também pela articulação com os outros níveis de atenção, contribuindo para a construção de um sistema de saúde integrado. Dentre suas propostas, em consonância com o SUS, o PSF está composto por uma equipe, que se propõe interdisciplinar, que atua inserida num território específico enfocando: a família, a integralidade do indivíduo, a intersetorialidade do serviço e a participação ativa da comunidade (Brasil, 1997).

Assim, o PSF tem o objetivo de contribuir para a reorientação das práticas em saúde, rompendo com o modelo de assistência que prevaleceu tradicionalmente em nossa sociedade: excludente, centrado na doença, individualizado e segmentado. Como a intervenção se dá no nível primário de atenção, ele trabalha localmente e, portanto, numa maior proximidade às famílias. $O$ acolhimento $e$ o vínculo são privilegiados e se caracterizam como uma modalidade de intervenção usuário-centrada, incentivada na proposta do SUS, para se que possa estabelecer uma relação interpessoal mais próxima dos usuários em suas demandas. Nesta perspectiva, a saúde é tomada num processo complexo envolvendo múltiplos fatores que podem favorecer ou impedir um estado saudável. Assim, a ênfase dada à assistência está embasada na proposta de um trabalho menos tecnificado e que privilegia uma maior proximidade com a comunidade.

Nesse sentido, alguns autores vêm enfatizando a importância do estudo dos processos saúde / doença, entendendo que a compreensão que se faz deste processo permeia toda a organização da prática em saúde e toda a relação do usuário com o sistema de saúde, suas crenças, seus modos de agir e sua adesão ou não aos cuidados em saúde. Minayo (1998), por exemplo, enfatiza que ao se propor uma ação em saúde a determinada população é importante que se esteja atento aos valores e crenças compartilhados pelo grupo. Oliveira (1998) também faz uma importante discussão sobre as concepções de saúde de uma comunidade. Segundo o autor, são esses entendimentos que embasam a maneira como as pessoas encaram a saúde e como lidam com a enfermidade, $e$ isso também se reflete na adesão ou não ao tratamento e na crença ou não no profissional que o acompanha. A eficácia de um trabalho com uma comunidade, ou com uma família em específico, depende do significado que este tem para ela, depende de ser algo

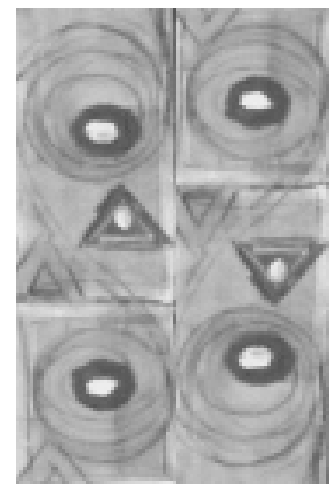


que ela busque e acredite fundamental para sua vida, sendo, portanto, imprescindível compreender os sentidos que essa comunidade/família dá para as situações de saúde/enfermidade em seus cotidianos. Entendemos que tal ênfase nos estudos dos processos saúde/doença implica a problematização de concepções universais e fixas sobre eles, convidando-nos a atentar às peculiaridades locais dessas concepções, o que poderá favorecer ações mais contextualizadas, valorizando as percepções e vivências da população a se intervir, e ajudando a refletir criticamente acerca de qual perspectiva fundamenta determinada ação em saúde (Tarride, 1998).

Objetivo

O presente estudo visa contribuir com o discurso da necessidade de um fazer-em-saúde embasado em práticas locais, democráticas e próximas à população e tem o objetivo de descrever sentidos de saúde/doença produzidos em grupos comunitários realizados no contexto de um Programa de Saúde da Família.

Método

O estudo teve o construcionismo social como base teórico-metodológica (Gergen, 1985, 1997; Shotter, 1993). Essa perspectiva compreende que os sentidos que as pessoas constroem sobre si mesmas e sobre o mundo são produzidos nas interações entre as pessoas, situadas em contextos históricos específicos, e sustentados pelos processos locais de negociação dos sentidos, sejam eles consensos ou disputas, em suas práticas cotidianas. Assim, a atenção em saúde é vista como uma prática social dentro de um contexto histórico e cultural, e cujos sentidos são permanentemente (re) construídos pelas interações entre profissionais e comunidade, imersos em universos de significação mais amplos já disponíveis, por exemplo, as políticas gerais de saúde.

A perspectiva construcionista social acerca da produção do conhecimento, compreende ainda a própria atividade de pesquisa como uma prática social (Spink, 1999) que ativamente constrói sentidos sobre seu objeto de estudo. Isso implica conceber o delineamento metodológico não como garantia de acesso aos fatos como eles são, mas como uma construção social que produz versões do mundo, "podendo ter maior ou menor poder performático dependendo do contexto de produção, do momento histórico, das relações sociais em que ocorre essa produção, aliados à intencionalidade de quem produz e o grau de conformidade de quem recebe" (Spink \& Medrado, 1999, p.61). Assim, esse estudo foi delineado buscando favorecer uma aproximação ao cotidiano de uma comunidade alvo de um PSF com uma área de abrangência de 1300 famílias de um bairro de classe média baixa, de uma cidade de grande porte no interior do Estado de São Paulo.

Foram realizados cinco grupos comunitários, reunindo moradores de uma mesma rua, em cinco ruas diferentes, escolhidas por critério geográfico dentro da área de abrangência do Programa. Os grupos foram de sessão única, com duração de cerca de uma hora e quinze minutos, com cinco a nove participantes cada um. Apesar de o convite para participar ter sido dirigido às famílias, os grupos foram compostos apenas por mulheres (idade 
média de cinqüenta anos) e bastante heterogêneos com relação às características sócio-demográficas (casadas, desquitadas e solteiras; desde analfabetas até universitárias; com atividades domésticas e/ou autônomas pouco qualificadas, e com vínculos empregatícios de longa duração). Assim, a composição dos grupos foi baseada na disponibilidade das participantes, considerando o critério geográfico e o convite familiar, após consentimento livre e informado (Conep, 1998), conforme aprovado por uma Comissão de Ética em Pesquisa.

Os grupos foram coordenados pela primeira autora que introduziu ativamente três temas: o que é estar com saúde, o que é estar doente, o que é cuidar da saúde. O manejo grupal consistiu na facilitação das conversações, pontuando as passagens consideradas relevantes para o tema, mantendo as discussões nos seus objetivos e, quando necessário, orientando quanto a dúvidas sobre o PSF. O procedimento de coleta de dados consistiu do registro áudio-gravado desses cinco grupos e das anotações de campo realizadas ao longo de um ano de contato com este Programa. Após a transcrição de todos os grupos, iniciou-se uma pré-análise que consistiu de leituras sucessivas das transcrições e das anotações, o que permitiu a elaboração de uma narrativa sobre cada grupo contendo uma descrição geral sobre o contexto, os principais temas discutidos, o padrão de interação grupal, a tonalidade afetiva, bem como o manejo da coordenadora (Camargo-Borges, 2002).

A análise propriamente dita envolveu: (1) o contato extensivo com o material transcrito buscando acompanhar o fluxo das conversações em cada tema proposto, o que permitiu a construção das semelhanças entre os grupos, assim como das especificidades de cada um. A partir deste processo, (2) focalizou-se a atenção em duas formas distintas de conversações: uma, em que as participantes falavam do lugar de pessoas que gozam de saúde; $e$ outra, em que elas falavam do lugar de pessoas adoecidas, necessitando de cuidados específicos. No primeiro caso, os temas geralmente envolviam concepções de saúde mais relacionadas aos discursos da promoção da saúde $e$, no segundo, as questões discutidas envolviam acesso, queixas $e$ insatisfações em relação ao sistema de saúde. Isso possibilitou (3) a construção de dois eixos temáticos, "quando a questão é promover saúde" $e$ "quando a questão é recuperar a saúde", em torno das quais o processo de análise foi construído. Definidos esses eixos, (4) foram selecionados recortes específicos a cada grupo, escolhidos pela sua relevância para pôr em evidência os múltiplos sentidos acerca de saúde/doença que circularam entre as participantes nessas conversações. A análise descritiva destes recortes (nomes fictícios), é apresentada a seguir.

Quando a questão é promover saúde

A análise deste primeiro eixo envolveu os momentos em que as participantes conversaram sobre como era levar uma vida com qualidade, de que era necessário cuidar para manter uma boa saúde e estar bem, o que consideravam que era estar doente e como lidavam com isso, enfim, como elas referiram tratar essas questões em seus cotidianos. Essas conversas traziam temas que associamos a sentidos referidos aos discursos da 
promoção da saúde em tantos contextos (profissionais, acadêmico, da mídia em geral) e o que mais chamou nossa atenção e foi objeto privilegiado de análise foram os desdobramentos desses temas nas conversações - que sentidos eram produzidos acerca do que é promover saúde? Nomeamos esses momentos de conversação com recortes de falas das próprias participantes do grupo, desenvolvidos em três temas: (1) "estar com problemas reflete na sua saúde", (2) "eu acho que tudo é tá de bem com a vida" e (3) "se não tiver saúde, não trabalha mesmo."

O primeiro deles, "estar com problemas reflete na sua saúde", refere momentos conversacionais em que a saúde foi descrita como o somatório de diversos fatores que movem o ser humano: o físico, o mental, emocional e o social. No exemplo abaixo, Mercedes, participante de um dos grupos, dá sua opinião sobre o que considera estar saudável:

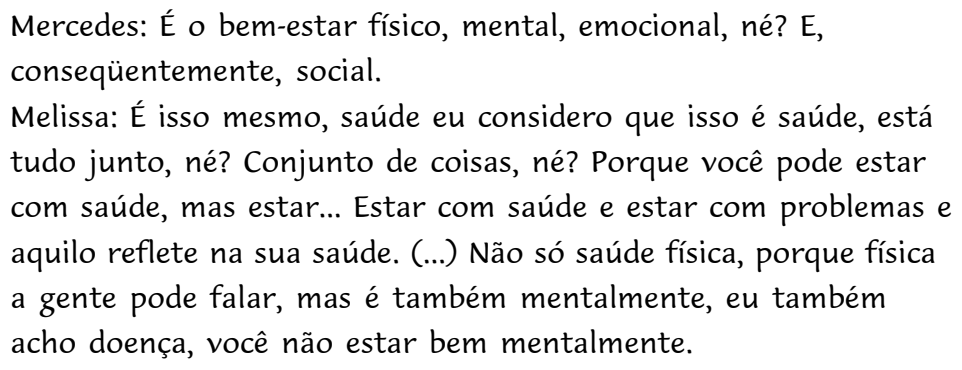

Nessa conversa, as participantes colocam em foco diversos aspectos envolvidos na questão da saúde integral. Num discurso biopsicossocial afinado, falam da importância do bem-estar físico, mental, emocional e social. No desenvolvimento dessas conversas, tais aspectos foram sendo descritos com existência separada, cada segmento refletindo sobre outro, formando um "conjunto de coisas" importantes, porém independentes, sendo necessário juntar as partes para resultar numa saúde integral.

O segundo tema, "eu acho que tudo é tá de bem com a vida", aborda momentos das conversações em que as participantes referem bons hábitos de vida como propiciadores de uma boa saúde. Promover saúde é significado como estar de bem com a vida e ter bons hábitos de vida contribui para se estar com saúde.

Em um dos grupos, conversando sobre a riqueza da alimentação como importante fonte para a saúde, as participantes trocam dicas sobre alimentos:

Inês: Come uma banana nanica todo dia de manhã.

Laura: Maçã...

Nilda: Couve, né?

Laura: Mamão, mamão é bom. (...)

Milena: Agora esses dias eu tenho mostarda lá. Nossa, precisa de vê pro intestino. Uma maravilha.

Celiane: Mostarda? (...)

Laura: O caldo da beterraba faz um suco também. Bom pra anemia. 
Celiane: É, é bom.

Laura: É... o... xarope pra bronquite... o caldo de beterraba bate no liquidificador, põe açúcar e faz ele de mel.

Essa conversa tem início associando uma boa alimentação à promoção da saúde e a uma boa qualidade de vida. Os alimentos que cada uma considera importantes para a saúde vão sendo citados. Porém, no desenvolver da conversação, esses sentidos mais associados aos discursos da promoção de saúde, vão sendo também produzidos em consonância com um discurso medicalizado. $\mathrm{O}$ alimento passa a ser referido como um remédio, associado a formas possíveis de cura das doenças, com sua utilização sendo relacionada a uma determinada patologia e não como fonte diária de nutrição e saúde.

O terceiro tema "se não tiver saúde, não trabalha mesmo" refere-se a momentos da conversação em que trabalho / desemprego foi vinculado diretamente ao processo saúde / doença, numa associação em que ter saúde é descrito como ter forças para o trabalho, enquanto estar doente leva ao desemprego.

No exemplo abaixo, o grupo discutia sobre o estar doente e suas conseqüências:

Celiane: E pra Dona Meire, pra Meila, que é estar doente? Meire: Eu tenho um lá [em casa] desempregado. Hoje que vai entrar de serviço. Num arrumô nada. (...) E ele também tem, é...sofre de pressão, ele cai. Ele desmaia, né Dona Melissa. Milena: Uai Dona Meire, então, ele desmaia, dá <tontura?> nele, como é que ele pode trabalhar?

Meire: Ele não pode. O homem já falou com ele que ele não pode mais subir em poste. E se dá aquele ... ele morre.

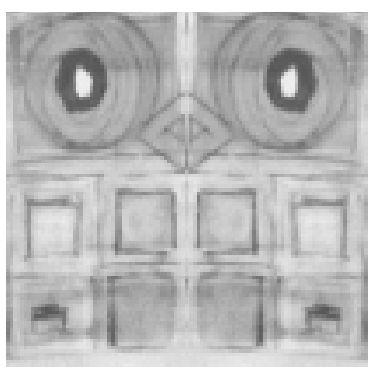

Nessa conversa, a saúde foi vinculada ao trabalho na medida em que é necessário ter saúde, estar com forças, para conseguir realizá-lo e, conseqüentemente, obter seu sustento. O adoecer estaria no pólo oposto, sendo a incapacidade para a realização do trabalho, trazendo, conseqüentemente, a perda do emprego - ficar desempregado como resultado de se estar doente. O desenvolvimento dessa conversa está pautado por uma lógica que é inversa à lógica dos discursos da promoção de saúde do trabalhador, relatados nas conferências nacionais e internacionais, nos quais a falta de emprego gera a exclusão social, comprometendo a cidadania da pessoa em seus direitos, e dessa maneira caracterizando-se como uma doença social. Para as participantes, a saúde gera emprego e a doença o desemprego de uma maneira bastante concreta, em referência aos seus cotidianos.

Na construção deste primeiro eixo da análise "quando a questão é promover saúde" recortamos, então, momentos das conversas grupais que entendemos como referidos a muitas das concepções presentes nos discursos mais atuais da promoção de saúde, mas também outros em que esses sentidos foram associados a um cuidado focado na doença. Buscamos assim, dar visibilidade aos múltiplos sentidos que se constroem sobre a 
questão da recuperação da saúde à medida que as conversações foram se desenvolvendo.

\section{Quando a questão é recuperar saúde}

No segundo eixo de análise privilegiamos conversas referidas à questão do autocuidado na saúde, focalizando momentos conversacionais em que as participantes, posicionando-se como pessoas fragilizadas ou adoecidas, conversavam sobre as diversas possibilidades do cuidado em relação à doença $e$ sua recuperação. No desdobramento das conversas, as queixas $e$ insatisfações com o sistema de saúde aparecem à medida que vão sendo relatadas diversas dificuldades no processo de se cuidar e de ser cuidado. Este eixo foi composto por três temas, que nomeamos como: "ela tá com saúde, tem até cartão do posto", "você pensa que eu tomei o remédio que a médica me deu?", "o que a gente entende por saúde e o que o médico considera saúde".

Incluímos no primeiro tema "ela tá com saúde, tem até cartão do posto" momentos das conversações em que as participantes discutem a questão autocuidado em relação à possibilidade de acesso aos serviços de saúde. Estar com saúde, nesses momentos de fragilidade, foi vinculado ao acesso às estruturas necessárias para que se obtenha a recuperação. Segue o exemplo:

Celiane: E esse desenvolvimento que a Luciana [filha] vai tendo, seria também estar com saúde!? [referindo a uma conversa sobre o bom desenvolvimento da filha na escola e em casa]

Lucélia: É. Ela tá com saúde, tem até cartão do Posto. Eu num tô metendo o pau no Posto não, porque, quando tive ela, assim de Pediatra,... que eu ganhei ela. Era ótima pessoa. Não tenho nada que falar dela. É a Dra. Elena. e a Dra. Tatiane. Ela que acompanha a menina.

Neste exemplo, Lucélia, participante de um grupo, associa ter cartão do posto a estar assegurada uma boa saúde. Em um outro momento da conversação, neste mesmo grupo, Geórgia inclui uma perspectiva um pouco diferente:

Giorgia: Eu tô falando que não adianta nada a gente querer correr atrás da saúde, querer se tratar, querer se cuidar, e não ter condições. E aí pode demorar muito. Quer dizer (...) às vezes é uma coisinha simples, aí se é um problema de pele, né? Aumenta os negócios, porque? Está demorando pra chamar. Ô... dermatologista, dentista, éé.... oftalmologista, psicólogo. É tudo muito demorado. Até acontecer as coisas, prolonga, por que? Porque demora. Quem não tem condições, o caso piora, né? Quer dizer, você precisa, estar ali, dependendo daquilo... demora. Eu mesmo com dermatologista...

Soraia: A área de oftalmo, dentista, dermatologista, vichi!

Aqui o acesso é posto em pauta sob outra perspectiva. As participantes 
concordam que a busca pela saúde não pode ser unilateral, dependendo somente delas, mas que esta também depende de um processo relacional entre usuário e profissional de saúde e de condições concretas de acesso aos profissionais de saúde.

Construímos o segundo tema "você pensa que eu tomei o remédio que a médica me deu?" tomando momentos das conversações em que as questões da não adesão ao tratamento ou da não continuidade deste foram descritas como autocuidado e não como displicência por parte dos pacientes.

Vivi: Não compro, não compro!!! [tom alterado]. Volto no outro médico. [Se referindo a remédios que o médico receita sem um exame adequado]. (...)

Silei: Eles te olham, você fala o que você tem e eles te dá. Eu já até sei o que eu vou tomar. Voltarem! Esse Voltarem já tomou conta da minha vida. Eu falo: “Não é possível!” Eu vou lá no Posto...

Lucélia: Você pensa que eu tomei o remédio que a médica me deu? No Posto? Tá fechadinho, em casa guardado. Quer dizer, eu não vou tomar esse remédio. Que ela não marcou a receita direito, não examinou nem nada. Como é que eu vou tomar esse remédio? Eu não posso tomar esse remédio! E eu não vou tomar!

Preocupadas com o que experimentam como a não escuta médica e com o que consideram um exame mal realizado, trazendo conseqüentemente, segundo elas, uma prescrição mal feita, as participantes contam que encontram como solução possível para sua proteção, não aderir às orientações profissionais. Considerando que as participantes não compartilham dos mesmos sentidos acerca do que seja uma boa prescrição ou um bom exame médico, essa conversa no grupo nos possibilita apreender sentidos diversos daquele que sustenta a concepção, bastante difundida, de uma população eminentemente ignorante e/ou resistente assistida pelo sistema público de saúde, que não exerce o autocuidado por não seguirem as "ordens médicas". Por uma outra perspectiva, essas participantes contam sobre uma grande preocupação com a saúde e, justamente por esse motivo, não poderiam aderir a um tratamento ou tomar um remédio que fosse orientado por um profissional que não as ouviu da forma que elas acreditavam ser imprescindível para uma correta compreensão de suas queixas.

A perspectiva de se pensar a não-adesão como uma forma de a pessoa se cuidar possibilita reconhecer um usuário comprometido com sua própria saúde; implica também repensar diferenças importantes na relação profissional/usuário, num contexto em que essas pessoas atravessam situações delicadas de desequilíbrio de suas saúde, situações que requerem o entendimento mútuo do que é importante e necessário no cuidado à saúde.

O terceiro e último tema do segundo eixo "o que a gente entende por saúde e o que o médico considera saúde" trata do desacordo que muitas vezes ocorre entre o se sentir doente e o ser considerado doente e vice-versa, que ocorre entre o paciente e os profissionais de saúde. Dois exemplos 
podem ilustrar:

Márcia: Igual um dia, né? A menina fazia dois dias que ela tava com febre. Eu levei ela na médica. A médica olhou e falou assim: "Não, sua filha não tem nada,um dia vai passar". Bom, a febre dela num cessou. No outro dia eu levei ela lá. Aí uma songa monga falou pra mim - nem é médica - ela falou assim pra mim: "Ai mãe, mas você me trouxe ela ontem, está trazendo ela de novo? Tem que trazer daqui três dias.” Eu falei: Mas tem muitas mães aí, que em três dias perde filho. Aí ela falou assim pra mim: "Mas se você sentar nesse banco aqui de fora, você vai ver que cada pessoa ela tem uma história pra contar”. É mesma coisa o médico... a mesma ladainha... (...)

Cira: Toda vez que você leva é aquelas coisa. Parece que o remédio não faz nem efeito.

Segundo exemplo:

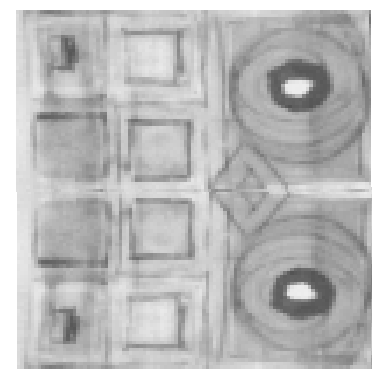

Nice: Um outro aspecto de saúde, é o que a gente entende por saúde e o que o médico considera saúde. Então isso é uma coisa assim, que eu já aprendi, que eu tenho uma experiência grande, porque às vezes, para o médico você é considerado um doente, né? Que nem no meu caso eu tenho hipertensão. Então, é considerado doença, né? Mas algumas vezes a gente consegue, mesmo tendo a enfermidade, quando bem controlada, se sentir saudável, né? A gente vê. Então eu acho que tem esse outro lado também, que às vezes a gente carrega muito esse peso da doença. "Não, eu... ah, eu sou doente, eu tenho isso, eu tenho, né?" Mas isso é o ponto de vista médico, mas muitas vezes você quando bem controlado, você se sente saudável.

No primeiro exemplo, Márcia conta uma situação em que acreditava ter a filha doente e sentiu-se desconsiderada e descuidada pelos profissionais no posto de saúde. Já no segundo exemplo, Nice conta uma situação inversa em que, sentindo-se saudável, foi considerada uma doente com limitações do ponto de vista médico. Em ambas as situações, o que foi considerado problema de saúde que merece atenção dependeu dos lugares ocupados nestas relações. Para os usuários, sentir-se doente ou com saúde é uma questão que está vinculada ao seu cotidiano, cujos sentidos são produzidos a partir de referências muitas vezes distintas daquelas dos profissionais de saúde. Para estes, o entendimento acerca daquilo que é um problema de saúde, e de como tratá-lo, é produzido em contextos discursivos muito distintos. Tais desacordos sustentam relações de descrença/desconfiança dos usuários em relação aos profissionais, ao tratamento e também ao próprio sistema de saúde, e vice-versa. Diferenças de entendimento que não negociadas, num sistema vertical de atenção à saúde, produzem, como conseqüência, críticas e insatisfações de ambas as partes, que restringem as possibilidades de produção de práticas compartilhadas de cuidado em saúde. 


\section{Considerações finais}

As conversas grupais analisadas favoreceram o entendimento de que as participantes demandam por um tipo específico de cuidado em saúde, dependendo do momento da vida em que se encontram. Quando falavam do lugar de pessoas saudáveis, a promoção de saúde foi o recurso privilegiado; porém, nos momentos em que discutiam alguma doença ou fragilidade, o acesso a serviços e intervenções profissionais para propiciar sua recuperação foi o instrumento requerido. Foi pela aproximação e conversação com essas participantes que se gerou a reflexão sobre os múltiplos sentidos produzidos em torno de tais temas e termos referentes à saúde em seus cotidianos. Nas conversas sustentadas pela necessidade de cuidados especializados, além da questão do acesso se fazer importante (consulta/remédio / exame), no nosso entender, o que se mostrou fundamental para as integrantes do grupo foi a dificuldade para acessar esses cuidados.

O olhar, nessa análise, esteve focado nos repertórios utilizados na construção desses sentidos acerca de saúde/doença, nos discursos presentificados no grupo e seus desdobramentos nas conversações das participantes. Podemos considerar que os novos discursos sobre saúde ampliada e integral estão presentes nas conversas grupais; porém, no modo como as participantes descreveram seus cotidianos nessas conversações, outros sentidos acerca do processo de saúde/doença, ainda bastante divergentes dos sentidos que produzimos no contato com as propostas atuais em saúde, foram construídos. Assim, buscamos dar visibilidade, nestas conversações situadas, aos diversos usos desses discursos nas conversas. Inicialmente, o desenvolvimento de cada tema estava sustentado na perspectiva dos discursos mais atuais da saúde, divulgados no meio científico, acadêmico e governamental, e voltados para a questão do autocuidado, da integralidade, da qualidade de vida e da cidadania. Em seguida, a conversa se desdobrava também pela recorrência a outros discursos disponíveis, como por exemplo, o da saúde medicalizada.

Entendemos, assim, que os dois eixos de análise desse estudo referem-se à questão da integralidade da atenção em saúde, sendo que o primeiro eixo focalizou a perspectiva da integralidade do ser humano e o segundo eixo, da integralidade do acesso ao sistema de saúde. Segundo Mattos (2001), a integralidade, no contexto do SUS, tem se desdobrado em uma diversidade de sentidos. Entre seus tantos possíveis - quer na organização dos serviços, nas práticas terapêuticas ou na orientação do trabalho - a integralidade sempre demanda uma atitude de recusa ao reducionismo, ao sujeito objeto, sempre buscando uma abertura ao diálogo.

Buscou-se com a análise proposta dar visibilidade ao como as usuárias participantes, nas histórias de si narradas no grupo, recorrem também ao discurso da integralidade na atenção em saúde. Elas conversaram sobre o processo saúde/doença abordando-o em seus múltiplos aspectos, tratando os diversos níveis de atenção como fundamentais e legítimos.

Concebendo, conforme propõe o construcionismo social (Spink, 1999; Gergen, 1985, 1997; Shotter, 1993), que o processo de produção de sentidos sobre o mundo, as coisas $e$ as pessoas está sustentado nas diferentes práticas sociais nas quais as pessoas participam, podemos pensar 
que as conversas grupais estão fortemente sustentadas pelas relações concretas dessas pessoas com as práticas locais em saúde, que vêm vivenciando ao longo do tempo, como usuárias dos serviços de saúde. Como práticas sociais situadas num sistema de saúde mais amplo, estas, apesar dos protocolos e discursos oficiais, não são produzidas num modelo de assistência inteiramente diverso da história que as constituíram. Entendemos, assim, que as participantes do grupo conversaram a partir deste lugar, usuárias de um serviço de saúde que convive com um discurso amplamente afinado com a integralidade da saúde, mas ao mesmo tempo com um discurso medicalizado da mesma.

Pela aproximação com essas pessoas nos grupos, no desdobramento dos diálogos e interlocuções, podemos problematizar que a mudança no modelo de atenção em saúde, incluindo ações como as privilegiadas pelo PSF, envolve o desafio da inclusão da participação de usuários que convivem também com as práticas e discursos mais tradicionais. A incorporação da conversa na relação profissional de saúde/usuário tem sido uma estratégia de mudança enfatizada e amplamente veiculada para a transformação do modelo de assistência à saúde (Andrade \& Vaistman, 2002; Vasconcelos, 1999; Anderson, 1996).

No entanto, os processos de interação entre profissionais e usuários, no contexto da saúde, têm sido pautados, muitas vezes, por concepções que permaneceram sedimentadas na tradição dum profissional portador do saber se relacionando com um usuário alienado deste saber com o intuito de educá-lo para um melhor comportamento em saúde. Essa relação, engessada pelas hierarquias, não parece contribuir para a transformação do sistema de saúde. Não se trata de negar as diferenças e a especificidade dos saberes da equipe. Trata-se de considerar o usuário também como portador de um saber específico, a partir do qual sua ação ganha sentido para ele.

$\mathrm{O}$ presente estudo pretendeu estimular uma reflexão sobre aspectos fundamentais para a emergência de novas possibilidades de interação na construção de práticas em saúde. Pelos eixos de análise foi possível visualizar a polissemia de discursos muitas vezes considerados universais sobre os cuidados em saúde. Desnaturalizá-los, enquanto discurso único, e explicitar como ele está sempre referido a contextos locais, produzindo a cada situação $e$ a cada encontro novos sentidos, convida-nos a ver os processos conversacionais como práticas sociais situadas que ajudam a (re) produzir um modelo compartilhado de atenção em saúde.

Conceber o processo saúde/doença como situado e contextualizado e, mais ainda, gerando uma rede de relações em que se constroem necessidades por meio de um processo dinâmico e dialógico entre as pessoas envolvidas, nos convida à construção de uma prática mais sensível às interações, à escuta e à permanente negociação entre equipe - comunidade.

Valoriza-se, assim, uma maior aproximação entre os atores sociais envolvidos, facilitando a abertura de espaços de conversação e de consensos, nos quais o diálogo seja a ferramenta-mestra da relação, possibilitando a construção de novos sentidos na especificidade da assistência local desejada.

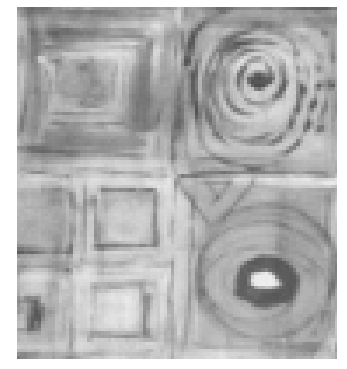


CAMARGO-BORGES, C.; JAPUR, M.

\section{Referências}

ANDERSON, H. Uma reflexão sobre a colaboração cliente-profissional. Fam. Syst. Health, n.14, p.193206, 1996.

ANDRADE G. R. B.; VAISTMAN, J. Apoio social e redes: conectando solidariedade e saúde. Ciênc. Saúde Coletiva, v.7, n. 4, p.925-34, 2002.

BRASIL. Ministério da Saúde. Secretaria de Assistência à Saúde. Coordenação de Saúde da Comunidade. Saúde da família: uma estratégia para a reorganização do modelo assistencial. Brasília, 1997.

BRASIL. Leis, Decretos. Portaria MS n.692, de 29 de Março. Dispõe sobre a oficialização do PSF.

Diário Oficial da União, n.060, 4572. Brasília, 1994.

BRASIL. Lei n. 8080, de 19 de Setembro. Dispõe sobre as condições para a promoção, proteção e recuperação da saúde, a organização e o funcionamento dos serviços correspondentes e dá outras providências. Diário Oficial da União, Brasília, MS 18055 - 9, 1990.

CAMARGO-BORGES, C. Sentidos de saúde/doença produzidos em grupo numa comunidadealvo do Programa de Saúde da Família (PSF). 2002. Dissertação (Mestrado) - Faculdade de Filosofia Ciências e Letras, Universidade de São Paulo, Ribeirão Preto.

CONEP. Resolução n¹96. Cad. Ética Pesqui., n.1, p.34-42. 1998.

GERGEN, K. J. The social constructionist movement in modern psychology. Am. Psychol., v.40, p.26675, 1985.

GERGEN, K. J. Relation and relationships: soundings in social construction. Cambridge/London: Harvard University Press, 1997.

MATTOS, R. A. Os sentidos de integralidade: algumas reflexões acerca dos valores que merecem ser defendidos. In: PINHEIRO, R.; MATTOS, R. A. (Org.) Os sentidos da integralidade na atenção e no cuidado. Rio de Janeiro: Abrasco, 2001. p.39-64.

MINAYO, M. C. S. O desafio do conhecimento: pesquisa qualitativa em saúde. São Paulo: Hucitec; Rio de Janeiro: Abrasco, 1998.

NUNES, E. D. Sobre a história da Saúde Pública: idéias e autores. Ciênc. Saúde Colet., n.5, p.251-64, 2000.

OLIVEIRA, F. J. A. Concepções de doença: o que os serviços de saúde têm a ver com isto? In: DUARTE L. F. D.; LEAL, O. F. (Org.) Doença, sofrimento, perturbação: perspectivas etnográficas. Rio de Janeiro: Fiocruz, 1998. p.81-94.

SHOTTER, J. Conversational realities: constructing life through language. London: Sage publications, 1993.

SPINK, M. J. (Org.) Práticas discursivas e produção de sentido no cotidiano. Aproximações teóricas e metodológicas. São Paulo: Cortez, 1999.

SPINK, M. J.; MEDRADO, B. Produção de sentidos no cotidiano: uma abordagem teórico-metodológica para análise das práticas discursivas. In: SPINK, M. J. (Org.) Práticas discursivas e produção de sentido no cotidiano: aproximações teóricas e metodológicas. São Paulo: Cortez, 1999. p.41-61.

TARRIDE, M. I. Saúde Pública: uma complexidade anunciada. Rio de Janeiro: Fiocruz, 1998.

VASCONCELOS, E. M. Educação popular e a atenção à saúde da família. São Paulo: Hucitec, 1999.

518 Interface - Comunic, Saúde, Educ, v.9, n.18, p.507-19, set/dez 2005 


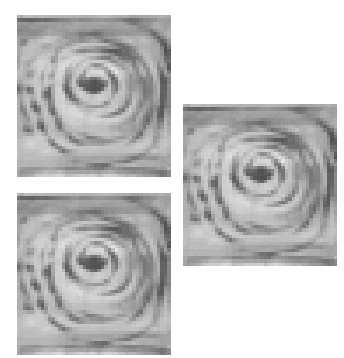

CAMARGO-BORGES, C.; JAPUR, M. Promover y recuperar salud: sentidos producidos en grupos comunitarios en el contexto del Programa de Salud de la Familia. Interface Comunic., Saúde, Educ., v.9, n.18, p.507-19, set/dez 2005.

La Salud Pública en Brasil ha acompañado grandes movimientos de cambio en su modelo asistencial de salud. Nuevas tendencias apuntan hacia la importancia de acciones construidas a partir de su contexto, direccionadas a comunidades específicas. El presente estudio tuvo por objetivo describir los sentidos de salud/enfermedad producidos en grupos comunitarios pertenecientes a un Programa de Salud Familiar. Han sido audiograbados cinco grupos de sesión única, coordinados por la primera autora. Los grupos fueran transcritos y junto a las notas de campo, constituíranse la base de datos. El análisis describió sentidos acerca de las nociones que basan las nuevas propuestas en salud, promoviendo visibilidad a la multiplicidad de sentidos, desnaturalizando discursos fijos sobre salud/enfermedad. Las consideraciones finales, basadas en la perspectiva del construccionismo social, apuntan hacia la fertilidad de una práctica en salud basada en los procesos de conversación y negociación constantes entre todos los actores sociales involucrados.

PALABRAS CLAVE: salud de la familia. servicios de salud comunitaria. construcionismo social. 